\title{
What would happen if we strew sugar in water or oil? Predictions and drawings of pre-schoolers
}

\author{
Maria-Antonia Panagiotaki, Konstantinos Ravanis \\ University of Patras, Department of Educational Sciences and Early Childhood Education,
}

Rion-Patras, 26500, Greece

\begin{abstract}
In this article, we will present a research on the tracing of pre-school students' mental representations on the phenomenon of dissolution of solids in a liquid. Thirty-one children drawn out of four different kindergarten classes participate in this research. The main subject of this research was the listing and ranking of 5-6 year old children's representations, when called to predict problems concerning the dissolution of a solid substance in two different liquids (water or oil). The approach was qualitative and the research was carried out based on personal interviews and children's drawings. The results showed that a significant percentage of the subject sample does not detect differences between the dissolution of sugar in water or oil, that there are major differences when children draw or predict and that while in their drawings children seem to comprehend the preservation of sugar in the solution, in their predictions many of them view that sugar is not preserved.
\end{abstract}

\section{Indexing terms/Keywords}

Mental representations, dissolution of a solid in a liquid, preschool age, kindergarten

\section{Academic Discipline And Sub-Disciplines}

Science Education; Preschool Education

TYPE (METHOD/APPROACH)

Qualitative approach; Survey/Interview

\section{Council for Innovative Research}

Peer Review Research Publishing System

International Journal of Research in Education Methodology

\author{
Vol.5, No.2 \\ editor@ijrem.com \\ www.cirworld.com,www.ijrem.com
}




\section{THEORETICAL FRAMEWORK}

The study of children's mental representations on concepts and phenomena in the natural world is for the past 20 years a field of study in preschool age as well, as it allows for the approach of their reasoning structures (Ravanis \& Papamichaël, 1995; Dedes \& Ravanis, 2009a, 2009b; Küçüköze, H. \& Bostan, A., 2010; Fyttas, Komis \& Ravanis, 2013). Researches that, apart from ranking and coding the representations, focus on children's thought structures that are frequently repeated and present data as well as relationships between data compatible with educational scientific knowledge are also important. Those structures are characterized as precursor models (Weil-Barais, 2001; Ravanis, Koliopoulos \& Boilevin, 2008; Canedo-lbarra et al., 2010). The study of those precursor models as well as of their formation process is of great importance as it allows, apart from the cognitive profiling of children in a certain field, the coming closer towards the scientific educational knowledge of a certain level (Fleer \& March, 2009; Gallegos Cázares, Flores Camacho \& Calderón Canales, 2009; Koliopoulos et al., 2009; Ergazaki, Zogza \& Grekou, 2009; Gasparatou \& Kampeza, 2012; Ravanis, Christidou \& Hatzinikita, 2013).

One of the cognitive areas that this research treats is the dissolution of a solid in a liquid. However, it appears that, as a systematic study of this phenomenon requires an approach of the microcosm, only a small number of researches uses preschool-aged children as subjects. Nevertheless, representations of children of slightly older age allow for the comprehension of not only the children's thoughts on dissolution, but also of the major obstacles they encounter.

In an effort to summarize the ideas of students on the phenomenon of dissolution, we study the descriptions of children of various ages, about what happens when sugar is strewed in water (Driver et al., 1994). Up until 8 years old, children seem to focus solely on the dissolved substance, claiming that it "simply goes away", "disappears", "melts", "dissolves" or "turns into water". The researchers report that when the answer "melts" is thoroughly examined, then a lot of the children tend to describe it in a way resembling to ice "becoming liquid". The results indicate that older students picture that when sugar is dissolved, "it turns into tiny bits". Later on, some believe that "the sugar molecules fill the gaps of water molecules", or differently "blend with the water molecules".

On the subject of preservation of the solute during dissolution, Holding's (1987) research indicates that initially, a percentage of students that steadily grows as the age increases, understands the preservation of the substance, whether a smaller percentage only gets to the preservation of weight. On this subject, Slone and Bokhurst (1992) studied 4-13 year old students' thinking and detected an instability, namely a fluctuation of the number of answers where, in that particular age scale, preservation is recognized, with a final reduction of the percentage in 12-13 years old.

Rosen \& Rosin (1993) studied 3-5 year old children's thoughts on dissolution of substances that, when dissolved in water, are not visible. This particular research attempts to confirm the findings of Piaget \& Inhelder (1974) concerning children's representations on the preservation of taste in a solution, despite their disbelief of the solute's preservation. The results indicated that children up to 3 years old recognize the transfer of a solute's properties to the solution in which it was dissolved, which confirms the findings of Piaget \& Inhelder on the transfer of properties during dissolution. However, contrary to Piaget \& Inhelder, clear evidence of preservation of matter in the majority of 4 year olds was traced in this research. Furthermore, Rosen \& Rosin observed an advanced recognition of invisible microscopic pieces into which the solute is separated and continues to exist in the solution. Yet another finding of the research is that the children's acquaintance with the sugar's solution as well as the rest of its solutions that they encounter in their daily life does not affect their thinking, as the same results concerning the preservation of the substance appeared in the rest -not known to the children- solutions. Even polymerized glucose, which is not sensorily traceable, appears to have its presence in the solution recognized by a large number of 5 year old children.

Furthermore, in a research among preschool age children, the researchers sought the types of explanations given on the phenomenon of dissolution (Christidou, Hatzinikitas \& Dimoudi, 2005; Christidou, 2006). Among other findings, the results indicated that the children are in a position to appeal to the properties of matter in a way that is compatible to school knowledge, while in some cases they gave animistic or teleological answers.

Prieto, Blanco and Rodriguez (1989) studied 11-14 year old students' thoughts on the nature of solutions. The results indicated that they use daily-life terminology and examples of solutions with familiar solids dissolving in liquids, they consider the solute very important and at the same time assigning a more passive role to the solvent, while their drawings revealed that for many of them, dissolution is not connected to the matter's molecular structure. Longden, Black and Solomon (1991), in studying the interaction between the knowledge gained in school and the representations that have been created in daily life on the concept of dissolution, using 11-14 year old students as subjects, came to the conclusion that the students that had a sound perception of dissolution on a daily life experience level were fewer than those that had a correct interpretation of dissolution on a molecular level. They also came to the conclusion that the consistency between the reasoning compatible with the scientific method and the one based on daily life experience was not improved.

As we observed through the analysis of relative bibliography, research with children older than 10 years old is sufficiently developed and is oriented towards the relation between macrocosm and microcosm during dissolution. On the contrary, with subjects up to 10 years old the approach of the dissolution phenomenon is limited and is mainly oriented towards matters of preservation of familiar substances when dissolved in water. Thus, in the research presented here, we looked into the mental representations of preschool age children on the phenomenon of dissolution, or not, of a solid substance in a liquid. With this research, we attempted to cross-check the data of certain techniques in order to form the representations of approximately 5-6 year old children in relation to school reference learning, which is formed for younger students with no mention to the microcosm, apart from the division of sugar into "tiny bits". 


\section{METHODOLOGICAL FRAMEWORK}

\section{The research process}

From a methodological standpoint, the research was qualitative. We carried out personal interviews with the subjects in a specially prepared space in the kindergarten, out of the classroom. The time during which we collected the data ranged from 5 to 10 minutes per subject. The subjects were asked for predictions on mixing sugar with water or oil and to draw the mixture's image on a paper that had already the drawing of a glass of water. At the same time, they were asked to explain their drawing and their way of thinking. The subjects' comments, when available, were recorded as notes next to their drawings. The conversations with the children were recorded. The data processing was carried out based on the transcribed text, the subjects' drawings and the researcher's observation protocols.

\section{Subjects}

The 31 subjects (M. T. 5,3 years) of the research were drawn from four public kindergartens in an urban area in Greece. The children had not previously engaged in any activities concerning dissolution. After an understanding with the teachers, we chose children that were willing to "play" with the researcher.

\section{The research questions}

The main questions of this particular research were as follows:

- What are the mental representations of children on the phenomenon of dissolution of sugar in water?

- What are the mental representations of children on the phenomenon of dissolution of sugar in oil?

- Are the mental representations recorded when the children discuss the dissolution of sugar in water and oil compatible to those when they draw those conditions?

- Are children their age in the condition to spontaneously form a precursor model on dissolution compatible to school scientific knowledge, and if so, what are its characteristics?

\section{RESULTS}

The first distinction that is made from the analysis of the children's drawings is related to the way sugar is pictured. Thus, sugar is sometimes depicted as an "discontinuous" material that is drawn with dots (Image 1) and sometimes as an "continuous" material, namely either in the shape of a lump of sugar (Image 2) or with a single color in a large part of the glass (Image 3).

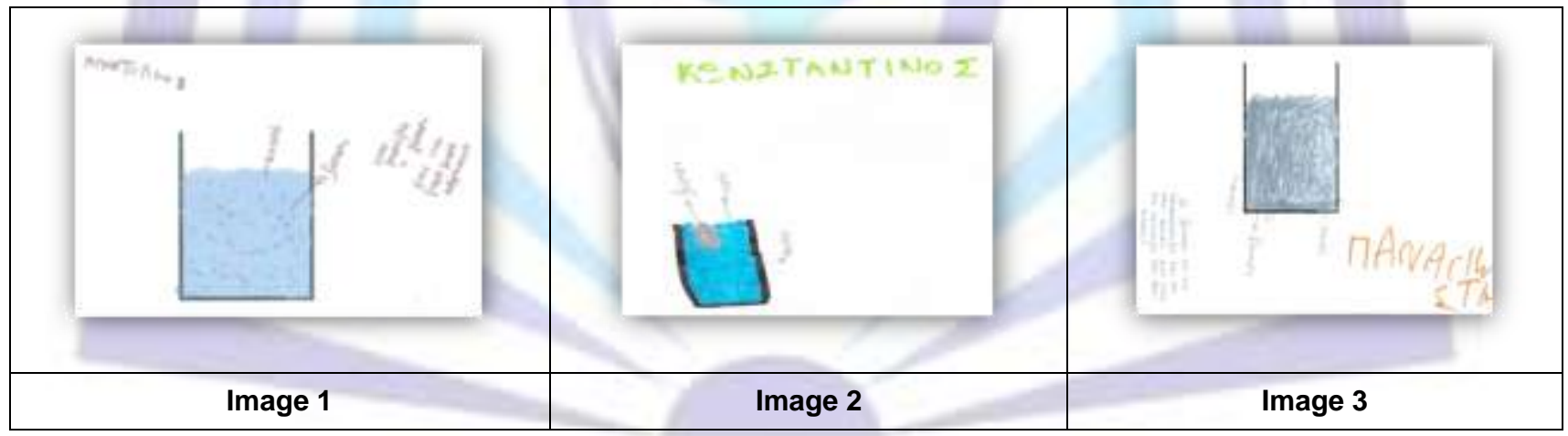

Another distinction made among the children's drawings regarded the point of concentration of sugar. Indeed, sugar is sometimes depicted as dispersed throughout the glass, while sometimes it is depicted concentrated in a certain area.

In Table 1, we present the categories that resulted from the study of the children's drawings. In this board, we carry out a double categorization using the way sugar is depicted and the point of its concentration as criteria. The points where sugar was pictured to be concentrated are symbolized in the board with a different character styling (Bold = sugar is in the bottom of the glass in the drawing, italics = sugar is in the center of the glass in the drawing, underlined $=$ sugar is high on the surface of the glass in the drawing).

As we can see, the majority of the children (40\%) depicts sugar as a discernible material dispersed throughout the glass in both systems. Even though regarding the "Water - Sugar" system, this specific way of depiction is compatible with the school precursor model, this doesn't apply for the "Oil - Sugar" system, as in this one, sugar is sunk at the bottom of the glass. It also appears that the majority of the children chooses to depict sugar as dispersed in both systems [53,3\% $(40+13,3)$ in the "Water - Sugar" system and 66,6\% $(40+26,6)$ in the "Oil - Sugar" system]. Thus, we can consider that the children choose the same way of depiction of sugar for both systems indiscriminately, as it appears that in the prediction phase they do not use a certain criterion with which they seem to discern the dissolution and non-dissolution states. 
Table 1. Analysis of children's drawings: categories and frequencies

\begin{tabular}{|c|c|c|c|c|}
\hline System & Categories & Subjects & Frequency (f) & Percentage \% \\
\hline \multirow{5}{*}{$\begin{array}{l}\text { Water - } \\
\text { Sugar }\end{array}$} & $\begin{array}{l}\text { Sugar as a discontinuous } \\
\text { material dispersed in all of the } \\
\text { glass' width }\end{array}$ & $\begin{array}{c}1,2,12,13,19-21,22 \\
25,26,29,30\end{array}$ & 12 & $40 \%$ \\
\hline & $\begin{array}{l}\text { Sugar as a continuous } \\
\text { material dispersed in all of the } \\
\text { glass' width }\end{array}$ & $6,11,24,28$ & 4 & $13,3 \%$ \\
\hline & $\begin{array}{c}\text { Sugar as a discontinuous } \\
\text { material concentrated in one } \\
\text { point }\end{array}$ & $\begin{array}{c}3,7,9,10,16 \\
18 \\
\underline{5} \\
\end{array}$ & $\begin{array}{l}5 \\
1 \\
1 \\
\end{array}$ & $\begin{array}{r}16,6 \% \\
3,3 \% \\
3,3 \% \\
\end{array}$ \\
\hline & $\begin{array}{c}\text { Sugar as a continuous } \\
\text { material concentrated in one } \\
\text { point }\end{array}$ & $\begin{array}{c}4,8,27 \\
17,23 \\
\end{array}$ & $\begin{array}{l}3 \\
2 \\
2\end{array}$ & $\begin{array}{l}10 \% \\
6,6 \% \\
\end{array}$ \\
\hline & $\begin{array}{c}\text { Indistinct/ Temperamental } \\
\text { drawings }\end{array}$ & 14,15 & 2 & $6,6 \%$ \\
\hline & Total & 30 & 30 & $100 \%$ \\
\hline \multirow{5}{*}{$\begin{array}{l}\text { Oil - } \\
\text { Sugar }\end{array}$} & $\begin{array}{c}\text { Sugar as a discontinuous } \\
\text { material dispersed in all of the } \\
\text { glass' width }\end{array}$ & $\begin{array}{c}1,2,7,9,13,19-21 \\
22,25,26,30\end{array}$ & 12 & $40 \%$ \\
\hline & $\begin{array}{c}\text { Sugar as a continuous } \\
\text { material dispersed in all of the } \\
\text { glass' width }\end{array}$ & $\begin{array}{c}6,8,11,12,14,24 \\
28,29\end{array}$ & 8 & $26,6 \%$ \\
\hline & $\begin{array}{c}\text { Sugar as a discontinuous } \\
\text { material concentrated in one } \\
\text { point }\end{array}$ & $\begin{array}{r}16,17 \\
18,27 \\
3,5,10 \\
\end{array}$ & $\begin{array}{l}2 \\
2 \\
\underline{3} \\
\end{array}$ & $\begin{array}{l}6,6 \% \\
6,6 \% \\
10 \% \\
\end{array}$ \\
\hline & $\begin{array}{c}\text { Sugar as a continuous } \\
\text { material concentrated in one } \\
\text { point }\end{array}$ & $\underline{23}$ & 1 & $3,3 \%$ \\
\hline & Indistinct Drawings & 4,15 & 2 & $6,6 \%$ \\
\hline & Total & 30 & 30 & $100 \%$ \\
\hline
\end{tabular}

In Table 2, we present the categories that were shaped from the children's answers during the interview.

Table 2. Children's answers in the prediction phase: will sugar exist in water or oil and will it be visible?

\begin{tabular}{|c|c|c|c|c|}
\hline System & Categories & Research Subjects & Frequency (f) & Percentage $\%$ \\
\hline \multirow{4}{*}{$\begin{array}{l}\text { Water - } \\
\text { Sugar }\end{array}$} & $\begin{array}{l}\text { Sugar will not be visible, but it } \\
\text { will exist }\end{array}$ & $\begin{array}{l}6,7,9,13,16,17,19 \\
21,24,25,26,28,30\end{array}$ & 13 & $41,9 \%$ \\
\hline & $\begin{array}{c}\text { Sugar will exist and will be } \\
\text { visible }\end{array}$ & $\begin{array}{c}1,3,4,5,8,10,11,12 \\
14,15,23,27\end{array}$ & 12 & $38,7 \%$ \\
\hline & $\begin{array}{c}\text { Sugar will neither be visible } \\
\text { nor will exist }\end{array}$ & $2,18,20,22,29,31$ & 6 & $19,3 \%$ \\
\hline & Total & $31(=N)$ & $31(=N)$ & $100 \%$ \\
\hline \multirow{5}{*}{$\begin{array}{l}\text { Oil - } \\
\text { Sugar }\end{array}$} & $\begin{array}{c}\text { Sugar will exist and will be } \\
\text { visible }\end{array}$ & $\begin{array}{c}3,4,5,6,10,11,12 \\
13,17,24,26,27 \\
\end{array}$ & 12 & $38,7 \%$ \\
\hline & $\begin{array}{c}\text { Sugar will not be visible, but it } \\
\text { will exist }\end{array}$ & $\begin{array}{c}7,8,14,16,21,23,25 \\
28,31\end{array}$ & 9 & $29 \%$ \\
\hline & $\begin{array}{c}\text { Sugar will neither be visible } \\
\text { nor will exist }\end{array}$ & $1,2,18-20,22,29,30$ & 8 & $25,8 \%$ \\
\hline & $\begin{array}{l}\text { Other answers i.e "If it's not } \\
\text { visible, it won't be visible" }\end{array}$ & 9,15 & 2 & $6,4 \%$ \\
\hline & Total & $31(=N)$ & $31(=N)$ & $100 \%$ \\
\hline
\end{tabular}

Here, it appears that a large percentage of the children has a sound perception of sugar's presence in both of the solutions and in both systems ("Water - Sugar": 41,9\%, "Oil - Sugar": $38,7 \%)$ ). An also large percentage of children (38,7\%) claims that sugar will be visible and exist in the water. In the "Oil - Water" system, a significant percentage of the children $(29 \%)$ answers that "it won't be visible, but sugar will exist". Furthermore, it is worth noting that and equally significant percentage of children $(19,3 \%$ and $25,8 \%)$ believes that "sugar will neither be visible nor will exist" in both systems. 
In Table 3, we present the results from the interview's question regarding where the sugar will be after we strew it in the glass.

Table 3. Children's answers in the prediction phase: where will sugar be when we strew it in water or oil?

\begin{tabular}{|c|c|c|c|c|}
\hline System & Categories & Research Subjects & Frequency (f) & $\begin{array}{c}\text { Percentage } \\
\% \\
\end{array}$ \\
\hline \multirow{5}{*}{$\begin{array}{l}\text { Water - } \\
\text { Sugar }\end{array}$} & Dispersed & $1,11,12$ & 3 & $9,7 \%$ \\
\hline & Bottom of glass & $\begin{array}{c}3-5,8-10,14-17,19 \\
21,23-26,28,30\end{array}$ & 18 & $58 \%$ \\
\hline & Center of glass & 6,27 & 2 & $6,5 \%$ \\
\hline & Surface of glass & 7,13 & 2 & $6,5 \%$ \\
\hline & Absence of sugar & $2,18,20,22,29,31$ & 6 & $19,3 \%$ \\
\hline \multirow{6}{*}{$\begin{array}{l}\text { Oil - } \\
\text { Sugar }\end{array}$} & Total & $31(=N)$ & $31(=N)$ & $100 \%$ \\
\hline & Bottom of glass & $\begin{array}{c}4,5,8,9,14,16,17 \\
21,23,25,27\end{array}$ & 11 & $35,5 \%$ \\
\hline & Dispersed & $10,12,13,15$ & 4 & $12,9 \%$ \\
\hline & Center of glass & $6,11,24,28,31$ & 5 & $16,1 \%$ \\
\hline & Surface of glass & $3,7,26$ & 3 & $9,7 \%$ \\
\hline & Absence of sugar & $1,2,18-20,22,29,30$ & 8 & $25,8 \%$ \\
\hline & Total & $31(=N)$ & $31(=N)$ & $100 \%$ \\
\hline
\end{tabular}

The majority of the children $(58 \%)$ in the "Water - Sugar" system regards that sugar will be at the bottom of the glass. At this point, we observe an inconsistency between the drawings and the children's answers to the interview question, as in the children's drawings it appears that $51,6 \%$ draws the sugar dispersed in the whole of the glass' width, while in the interview only $9,7 \%$ answers that sugar will be dispersed throughout the glass. The same applies to the "Oil - Sugar" system, as in the drawing 20/30 of the children drew the sugar dispersed, while in the interview 11/31 of the children answer that it will be at the bottom of the glass. The "Absence of sugar" category includes the subjects that answered negatively to the question of whether we will find sugar in the solution. Thus, it was logical that they were not required to be asked on the location of the sugar.

\section{DISCUSSION}

As we observed, in the "Water - Sugar" solution, 12/30 of the children draw and 13/31 children predict that sugar will be dispersed as a discontinuous material in the whole glass. However, only 6 of those kids draw and answer correctly at the same time.

Continuing with the "Oil - Sugar" system, in the prediction phase concerning the drawing only 2/30 children predict correctly, that is to say they draw the sugar as a discontinuous material, concentrated at the bottom of the glass. The majority of the subjects (4/10) uses the same prediction scheme that it used for the "Water - Sugar" system. Thus, it appears that the children use the same prediction scheme in their drawings, for both systems indiscriminately. However, we recorded in the discussion that more than $1 / 3$ of the children $(38,7 \%)$ predict correctly that sugar will be visible and exist in oil.

The differences that appear between the drawings and the predictions are also interesting as far as the preservation of sugar as a substance in water or oil goes. Indeed, while all of the children draw sugar in their drawings, when we ask them for a prediction on whether it will exist in water or oil, $1 / 5$ and 1/4 of the children respectively answered that it will not exist. This differentiation will have to be attributed to the different representation systems at work in children's thinking when they depict a situation or when they have to orally answer a question posed.

The last question that we posed is related to the children's capability of spontaneously constructing a precursor model on dissolution. Obviously, children encounter difficulties in structuring in their thinking a form of approach of the phenomenon of dissolution of a solid in a liquid, that will start from the testing of the materials and will maintain some steady elements, based on which they will carry out their assessments. Therefore, it seems impossible to presume that the construction of a precursor model on dissolution is feasible at the ages of 5-6 years old.

However, it would be of particular interest to study not only the predictions but also the explanations and descriptions of children on the dissolution of a solid in a liquid, when called to experiment with various materials. Such an approach would allow us to sufficiently map children's difficulties, based on which we can create educational material and instruct preschool teachers in formal and non-formal environments (Karalis \& Koutsonikos, 2003; Karalis, Sotiropoulos \& Kampeza, 2007; Koustourakis, Pefani \& Panagiotakopoulos, 2010). The research we are presently carrying out moves towards this direction. 


\section{REFERENCES}

[1] Canedo-Ibarra, S. P., Castelló-Escandell, J., García-Wehrle, P. \& Morales-Blake, A. R. (2010). Precursor models construction at preschool education: an approach to improve scientific education in the classroom. Review of Science, Mathematics \& ICT Education, 4(1), 41-76.

[2] Christidou, V. (2006). Accounting for Natural Phenomena. Explanatory modes used by children. International Journal of Learning, 12(8), 21-28.

[3] Christidou, V., Hatzinikitas, A. \& Dimoudi, A. (2005). Explanatory modes and their consistency in early childhood. In D. Koliopoulos \& A.Vavouraki (Eds), Science Education at Cross Roads: Meeting the Challenges of the 21st Century. Athens: Association for Science Education.

[4] Dedes, C. \& Ravanis, K. (2009a). Teaching image formation by extended light sources: The use of a model derived from the history of science. Research in Science Education, 39(1), 57-73.

[5] Dedes, C. \& Ravanis, K. (2009b). History of science and conceptual change: the formation of shadows by extended light sources. Science \& Education, 18(9), 1135-1151.

[6] Driver, R., Squires, A., Rushworth, P. and Wood-Robinson, V. (1994). Making sense of secondary science research into children's ideas. London \& New York: Routledge.

[7] Ergazaki, M., Zogza, V. \& Grekou, A. (2009). From preschoolers' ideas about decomposition, domestic garbage fate and recycling to the objectives of a constructivist learning environment in this context. Review of Science, Mathematics and ICT Education, 3(1), 99-121.

[8] Fleer, M. \& March, S. (2009). Engagement in science, engineering and technology in the early years: A culturalhistorical reading. Review of Science, Mathematics and ICT Education, 3(1), 23-47.

[9] Fyttas, G. Komis, V. \& Ravanis, K. (2013). Ninth grade students' mental representations of the refraction of light: didactic implications. Revista Mexicana de Fisica E, 59(2), 133-139.

[10] Gallegos Cázares, L., Flores Camacho, F., \& Calderón Canales, E. (2009). Preschool science learning: the construction of representations and explanations about color, shadows, light and images. Review of Science, Mathematics and ICT Education, 3(1), 49-73.

[11] Gasparatou, R. \& Kampeza, M. (2012). Introducing P4C in Kindergarten in Greece. Analytic Teaching and Philosophical Praxis, 33(1), 72-82.

[12] Holding, B. (1987). Investigation of school children's understanding of the process of dissolving with special reference to the conservation of matter and the development of atomistic ideas. PhD Thesis, University of Leeds, Leeds.

[13] Karalis, T., Sotiropoulos, L. \& Kampeza, M. (2007). La contribution de l'éducation tout au long de la vie et de l'anthropologie dans la préparation professionnelle des enseignants : réflexions théoriques, Skholê, HS(1), 149-155.

[14] Karalis, T., \& Koutsonikos, G. (2003). Issues and Challenges in Organizing Web-based Courses for Adults. Themes in Education, 4(2), 177-188.

[15] Koliopoulos, D., Christidou, V., Symidala, I. \& Koutsoumba, M. (2009). Pre-energy reasoning in pre-school children. Review of Science, Mathematics and ICT Education, 3(1), 123-140.

[16] Koustourakis, G., Pefani, I. \& Panagiotakopoulos, C. (2010). Exploiting television in Open and Distance Learning: The case of undergraduate courses in cultural studies at the Hellenic Open University. Open Education - The Journal for Open and Distance Education and Educational Technology, 6(1/2), 67-79.

[17] Küçüköze, H. \& Bostan, A. (2010). Ideas of kindergarten students on the day-night cycles, the seasons and the moon phases. Journal of Theory and Practice in Education, 6(2), 267-280.

[18] Longden, K., Black, P. \& Solomon, J. (1991). Children's interpetation of dissolving. International Journal of Science Education, 13(1), 59-68.

[19] Piaget, J. \& Inhelder, B. (1974). The child's construction of quantities. London: Routledge and Kegan Paul Ltd.

[20] Prieto, T., Blanco, A. \& Rodriguez, A. (1989). The ideas of 11 to 14-year-old students about the nature of solutions. International Journal of Science Education, 11(4), 451-463.

[21] Ravanis, K. \& Papamichaël, Y. (1995). Procédures didactiques de déstabilisation du système de représentation spontanée des élèves pour la propagation de la lumière. Didaskalia, 7, 43-61.

[22] Ravanis, K. Koliopoulos, D. \& Boilevin, J.-M. (2008). Construction of a precursor model for the concept of rolling friction in the thought of preschool age children: A socio-cognitive teaching intervention. Research in Science Education, 38(4), 421-434.

[23] Ravanis, K. Christidou, V. \& Hatzinikita, V. (2013). Enhancing conceptual change in preschool children's representations of light: a socio-cognitive approach. Research in Science Education, 43(6), 2257-2276.

[24] Rosen, A. \& Rosin, P. (1993). Now you see it, now you don't .The pre-scool child's conception of invisible particles in the context of dissolving. Developmental Psychology, 29(2), 300-311. 
[25] Slone, M. \& Bokhurst, F. (1992). Children's understanding of sugar water solutions. International Journal of Science Education, 14(2), 221-235.

[26] Weil-Barais, A. (2001). Constructivist approaches and the teaching of science. Prospects, 31(2), 187-196. 